\title{
Tubercular meningitis with hydrocephalus with HIV co-infection: role of cerebrospinal fluid diversion procedures
}

\author{
Raman Mohan Sharma, MBBS, MCh, Nupur Pruthi, MBBS, MCh, \\ Arivazhagan Arimappamagan, MBBS, MCh, Sampath Somanna, MBBS, MCh, \\ Bhagavathula Indira Devi, MCh, and Paritosh Pandey, MCh
}

Department of Neurosurgery, National Institute of Mental Health and Neuro Sciences, Bangalore, India

\begin{abstract}
OBJECT Hydrocephalus is one of the commonest complications of tubercular meningitis (TBM), and its incidence is increasing with the HIV epidemic. Literature evaluating the role of ventriculoperitoneal shunts in HIV-positive patients with TBM and their long-term prognosis is scarce.
\end{abstract}

METHODS Between June 2002 and October 2012, 30 HIV-positive patients with TBM and hydrocephalus underwent ventriculoperitoneal shunt placement. Thirty age-, sex-, and grade-matched HIV-negative patients with TBM and hydrocephalus were randomly selected as the control group. Outcome was analyzed at discharge (short-term outcome) and at follow-up (long-term outcome). Univariate and multivariate analyses were performed to look for predictors of outcome; $p$ $<0.05$ was considered significant.

RESULTS There were no differences in the clinical, radiological, or biochemical parameters between the 2 groups. Short-term outcome was better in the HIV-negative group (76.7\% improvement) than in the HIV-positive group (70\%). However, the long-term outcome in HIV-positive patients was very poor (66.7\% mortality and $76.2 \%$ poor outcome) compared with HIV-negative patients (30.8\% mortality and $34.6 \%$ poor outcome). Seropositivity for HIV is an independent predictor of poor outcome both in univariate and multivariate analyses $(p=0.038)$. However, in contrast to previous reports, of 5 patients with TBM in good Palur grades among the HIV-positive patients, 4 (80\%) had good outcome following shunt placement.

CONCLUSIONS The authors recommend that shunt treatment should not be performed in HIV-positive patients in poor Palur grade with hydrocephalus. A trial of external ventricular drainage should be undertaken in such patients, and shunt treatment should be performed only if there is any improvement. However, HIV-positive patients in good Palur grades should undergo VP shunt placement, as these patients have better outcomes than previously reported.

http://thejns.org/doi/abs/10.3171/2014.12.JNS14257

KEY WORDS tubercular meningitis; HIV; hydrocephalus; shunt

$\mathrm{T}$ UBERCULOSIS is an endemic disease in developing countries and is a major public health problem. The widespread increase in the prevalence of HIV infection has brought about a resurgence of tubercular infections in the developed world, and has caused an increase in tuberculosis in the developing world. ${ }^{13}$ Previous research and an existing knowledge base indicates that the incidence of tubercular meningitis (TBM) worldwide is increasing primarily because of the epidemic of HIV infection. ${ }^{2,3}$ HIV infection increases the risk of all forms of tuberculosis, especially extrapulmonary tuberculosis and TBM. Many previous reports have documented that HIV infection significantly reduces the survival rate in patients with TBM. ${ }^{12}$

Hydrocephalus is one of the most common complications of TBM, with close to $80 \%$ of patients having dilated ventricles in the early stages of the disease. ${ }^{23}$ Literature regarding the precise criteria for CSF diversion in patients with TBM with hydrocephalus remains controversial, as there is a dearth of well-designed prospective trials. ${ }^{6,19,27}$ Most of the literature supports the role of CSF diversion in patients with hydrocephalus who are in good grades (Grades I and II), ${ }^{1,19}$ however, the benefit for patients with hydrocephalus in poor grades is not definite. ${ }^{14,20}$ There is

ABBREVIATIONS GCS = Glasgow Coma Scale; GOS = Glasgow Outcome Scale; TBM = tubercular meningitis; VP = ventriculoperitoneal.

SUBMITTED February 4, 2014. ACCEPTED December 18, 2014.

INCLUDE WHEN CITING Published online February 13, 2015; DOI: 10.3171/2014.12.JNS14257.

DISCLOSURE The authors report no conflict of interest concerning the materials or methods used in this study or the findings specified in this paper. 
recent literature supporting the role of CSF diversion even in patients in Grade IV TBM..$^{22}$ However, literature evaluating the role of CSF diversion in HIV-positive patients with TBM and hydrocephalus is scarce. Nadvi et al. reported a series of 30 patients with TBM and hydrocephalus, of whom 15 were HIV positive. ${ }^{18}$ The authors reported very poor results following CSF diversion in their subpopulation. On the basis of the poor results following shunt placement in HIV-positive patients with TBM, the authors recommended against CSF diversion in this population, regardless of patient grade. ${ }^{18}$ There are no other studies describing the role of ventriculoperitoneal (VP) shunts in HIV-positive patients with TBM and hydrocephalus.

We have previously described our experience with shunts in poor-grade patients with TBM. ${ }^{13}$ The present study analyzes our experience of VP shunts in HIV-positive patients with TBM and hydrocephalus and correlates the outcome.

\section{Methods}

This retrospective study was performed at the National Institute of Mental Health and Neuro Sciences, Bangalore, India, and comprised HIV-positive patients with TBM and hydrocephalus who were treated with CSF diversion. All HIV-positive patients with TBM and hydrocephalus $(\mathrm{n}=30)$ who underwent VP shunt placement from June 2002 through October 2012 were included in this study. HIV-positive patients were diagnosed on the basis of a positive serological report by enzyme-linked immunosorbent assay or Western blot, or both. Thirty age-, sex-, and clinical grade-matched HIV-negative patients with TBM and hydrocephalus, who underwent CSF diversion in the same study period, were randomly selected as the control group. All patients who underwent VP shunt placement had symptoms of raised intracranial pressure, with clinical, radiological, and CSF findings characteristic of TBM. The clinical, biochemical, and CSF data were collected from the case records. The radiological features were reviewed from the radiology archives.

\section{Study Protocol}

All patients with TBM were started on a weight-appropriate dosage of antitubercular treatment, consisting of rifampicin, isoniazid, pyrazinamide, and ethambutol, along with pyridoxine supplements and steroids. The diagnosis of TBM was confirmed in all cases with plain and contrast-enhanced CT scans and cytochemical analysis of the CSF obtained from a lumbar puncture.

\section{Clinical Status}

The clinical status of the patients was defined at the time of admission based on Glasgow Coma Scale (GCS) scores $^{24}$ and Palur grade (Table 1) ${ }^{19}$ Other parameters that were analyzed were age, clinical grade at admission, duration of symptoms, CSF cellularity and proteins, duration of seropositivity (in patients with known HIV status), neurological deficits, presence of extrapulmonary tuberculosis, CT scanning evidence of basal exudates, hydrocephalus and infarcts, and CD4 count whenever available.
TABLE 1. Palur grading of tubercular meningitis

\begin{tabular}{cc}
\hline Grade & Definition \\
\hline I & $\begin{array}{c}\text { Headche, vomiting, fever w/ or w/o neck stiffness; no neuro- } \\
\text { logical deficits }\end{array}$ \\
\hline II & Normal sensorium; neurological deficits present \\
\hline III & $\begin{array}{c}\text { Altered sensorium but easily arousable; dense neurological } \\
\text { deficits may or may not be present }\end{array}$ \\
\hline IV & Deeply comatose; decerebrate or decorticate posturing \\
\hline
\end{tabular}

\section{VP Shunt}

As has been our policy, we prefer to place VP shunts in most patients with TBM and hydrocephalus after correcting any derangement in their biochemical parameters. This policy has given us good results even in Grade IV patients with hydrocephalus, where $45 \%$ of the poor-grade patients had good long-term outcome. ${ }^{22}$ However, if the patient had extensive basal infarcts secondary to arteritis in TBM, shunt placement was deferred and an external ventricular drain was placed; shunting was performed if there was improvement in the sensorium after CSF drainage. All patients underwent placement of a medium-pressure Chhabra VP shunt (Surgiwear Inc.). The external ventricular drains were placed in the frontal horn wherever applicable $5 \mathrm{~cm}$ above the external auditory meatus in all patients.

\section{Follow-Up}

Follow-up analysis was obtained from the medical records, through structured questionnaires, or by telephone conversation. Most of our patients were discharged 2-4 days after shunt placement and were referred to a hospital specializing in HIV-related treatment for further management. Whenever there was no hospital follow-up, a standard questionnaire was administered by telephone to determine the patient's outcome. Inquiries regarding improvement in sensorium and current health status and the patient's ability to perform daily work were obtained. In case of death, the duration between the death and the time of discharge and cause of death were recorded.

Outcome was analyzed at 2 points: outcome at discharge (short-term outcome) and outcome at follow-up (long-term outcome). The short-term outcome is more a function of immediate improvement secondary to CSF diversion, as the medical treatment would not have acted so soon. A good outcome was considered when there was improvement in the sensorium as determined by a 2-point improvement in GCS score, or there was improvement in raised intracranial pressure symptoms in fully conscious patients. The long-term outcome was assessed at 3 months after shunt insertion. The long-term outcome would be a function of both CSF diversion and treatment with antitubercular therapy and antiretroviral therapy, and the natural history of the disease. The long-term outcome was defined based on the Glasgow Outcome Scale (GOS) score. ${ }^{8}$ The outcome was considered good when there was good or moderate recovery (GOS Score 4 or 5) and poor when there was severe disability, persistent vegetative state, or death (GOS Scores 1-3). 


\section{Statistical Analysis}

Statistical analysis was performed using commercially available statistical software (SPSS 19.0; SPSS, Inc.). Chisquare tests were done for assessing the association between study variables and outcome. Multivariate analysis with binary logistic regression analysis was performed to look for the predictors of long-term outcome; $p<0.05$ was considered to be significant.

\section{Results \\ Demographic Data}

From June 2002 through October 2012, 30 HIV-positive patients with TBM and hydrocephalus underwent VP shunt placement. Thirty age- and sex-matched HIV-negative patients with TBM and hydrocephalus who underwent VP shunt insertion during the same time period were used as the control group. The mean and median ages in the HIV-positive group were 31.3 and 32.0 years, respectively (range 18-45 years), while the mean and median ages in HIV-negative patients were 31 and 29 years, respectively (range 18-62 years). In the HIV-positive group $73.3 \%$ were male, while in the HIV-negative group $76.7 \%$ were male.

\section{Clinical Presentation}

The clinical features of the cohort are tabulated in (Table 2). The incidence of history of tuberculosis was similar in both groups (40\% in the HIV-positive group vs $46.7 \%$ in the HIV-negative group). Headache was the most common presenting symptom in both groups $(73.3 \%$ and 76.7\% in HIV-positive and HIV-negative groups, respectively). Fever was present in fewer HIV-positive patients $(60 \%)$ than in HIV-negative patients $(86.7 \%)$. Seizure at presentation was more common in the HIV-positive group (7 patients [23.3\%]) than in the HIV-negative group (4 patients [13.3\%]). The majority of patients $(20$ [66.7\%] in the HIV-positive group and 18 [60\%] in the HIV-negative group) were in Palur Grade III. There was no statistically significant difference between the 2 groups with respect to the clinical parameters except in terms of constitutional symptoms and fever, which were in higher proportion in HIV-negative patients, and meningeal signs, which were more prevalent in HIV-positive patients. The incidence of extrameningeal tuberculosis was higher in the HIVpositive group (15 patients: 10 pulmonary and 5 extrapulmonary) than in the HIV-negative group (11 patients: 7 pulmonary and 4 extrapulmonary).

\section{Radiological Findings}

Preoperatively, all patients underwent plain and contrast-enhanced head CT scanning. The majority of the patients had communicating hydrocephalus (23 HIV-positive patients [76.6\%] and $22 \mathrm{HIV}$-negative patients [73.3\%]). Basal exudates were less common in HIV-positive patients $(\mathrm{n}=13[43.3 \%])$ than in HIV-negative patients $(17$ [56.6\%]). Infarcts were present in 7 HIV-positive patients (23.3\%) and $9 \mathrm{HIV}$-negative patients (30\%). Tuberculomas were seen more commonly in HIV-negative patients than in HIV-positive patients (Table 2). However, none of these
TABLE 2. Comparison of clinical, laboratory, and radiological features in HIV-infected and HIV-uninfected patients with tubercular meningitis*

\begin{tabular}{|c|c|c|c|}
\hline Variable & HIV Positive & HIV Negative & $\mathrm{p}$ Value \\
\hline \multicolumn{4}{|l|}{ Clinical features } \\
\hline Age in yrs & & & 0.758 \\
\hline Mean \pm SD & $31.30 \pm 7.8$ & $31 \pm 9.9$ & \\
\hline Range & $18-45$ & $18-62$ & \\
\hline Male sex & $22(73.3)$ & $23(76.7)$ & 0.766 \\
\hline Previous tuberculosis & $12(40)$ & $14(46.7)$ & 0.602 \\
\hline \multicolumn{4}{|l|}{ Duration of illness in days } \\
\hline Median & 15 & 16.5 & \\
\hline Range & $2-180$ & $2-180$ & \\
\hline Headache & $22(73.3)$ & $23(76.7)$ & 0.766 \\
\hline Constitutional symptoms & $18(60)$ & $26(86.7)$ & 0.020 \\
\hline Seizures & $7(23.3)$ & $4(13.3)$ & 0.317 \\
\hline Preop GCS score & & & 0.161 \\
\hline Mean \pm SD & $11.27 \pm 2.36$ & $12.50 \pm 2.22$ & \\
\hline Range & $5-15$ & $7-15$ & \\
\hline $3-8$ & $4(13.3)$ & $1(3.3 \%)$ & \\
\hline $9-15$ & $26(86.7)$ & $29(96.7)$ & \\
\hline Palur grade & & & 0.335 \\
\hline I & $4(13.3)$ & $7(23.3)$ & \\
\hline II & $2(6.7)$ & $4(13.3)$ & \\
\hline III & $20(66.7)$ & $18(60)$ & \\
\hline IV & $4(13.3)$ & $1(3.3 \%)$ & \\
\hline Meningeal sign (\%) & $24(80)$ & $14(46.2)$ & 0.007 \\
\hline Cranial nerve palsy (\%) & $7(23.1)$ & $9(30)$ & 0.559 \\
\hline Focal weakness (\%) & $6(20)$ & $10(33.3)$ & 0.243 \\
\hline \multicolumn{4}{|l|}{ Blood investigation } \\
\hline CD4 count (range) & $143(26-445)$ & Not done & \\
\hline Hyponatremia & $7(23.3)$ & $5(16.7)$ & 0.519 \\
\hline \multicolumn{4}{|l|}{ CSF features } \\
\hline CSF cell & & & 0.382 \\
\hline Median & 88.42 & 70.4 & \\
\hline Range & $0-112$ & $0-288$ & \\
\hline Glucose level in mg/dl & & & 0.396 \\
\hline Median & 56.0 & 43.00 & \\
\hline Range & $13-164$ & $15-94$ & \\
\hline Protein in mg/dl & & & 0.435 \\
\hline Median & 233.5 & 171 & \\
\hline Range & $54-357$ & $36-1592$ & \\
\hline \multicolumn{4}{|l|}{ CT scanning features } \\
\hline $\begin{array}{l}\text { Communicating hydro- } \\
\text { cephalus }\end{array}$ & 23 & 22 & 0.766 \\
\hline Exudates & 13 & 17 & 0.302 \\
\hline PVL & 25 & 26 & 0.718 \\
\hline Infarct & 7 & 9 & 0.559 \\
\hline Tuberculoma & 3 & 7 & 0.166 \\
\hline
\end{tabular}

$\mathrm{PVL}=$ paraventricular lucency.

* Values are number of patients (\%) unless indicated otherwise. Values in boldface are statistically significant. 
differences in the radiological parameters between the 2 groups were statistically significant.

\section{Blood and CSF Findings}

Hyponatremia was present in $7 \mathrm{HIV}$-positive patients (23.3\%) and in 5 HIV-negative patients (16.7\%). This difference was not statistically significant (Table 2). CD4 counts were available for only 21 patients in the HIV-positive group and ranged from 26 to 445 cells $/ \mathrm{mm}^{3}$ (mean 175.4 cells $/ \mathrm{mm}^{3}$; median 143 cells $/ \mathrm{mm}^{3}$ ) (Table 3 ).

The median CSF cell counts were slightly higher in the HIV-positive group ( 88.4 vs 70.4 cells $/ \mathrm{mm}^{3}$ ). The median glucose and protein values were slightly more in the HIVpositive group as shown in (Table 2). However, these differences were not statistically significant.

\section{Follow-Up Analysis}

Follow-up or last known outcome (including death) was available for 21 of the $30 \mathrm{HIV}$-positive patients with a mean follow-up of 130 days (range 3-25 months). In the HIV-negative group, follow-up or last known outcome was available in 26 patients, with a mean follow-up of 154 days (range 3-48 months). A case-bias analysis was done between the follow-up group and the complete group, and it showed that the clinical grade, age, and sex were similar in both groups, thus showing that this follow-up group is representative of the entire group.

\section{Short-Term Outcome}

Short-term outcome was assessed at the time of discharge (range 2-7 days, mean 3.5 days) after VP shunt implantation. Most of the patients improved after CSF diversion and exhibited improvements in GCS score and neurological symptoms. There was a slightly better shortterm outcome in the HIV-negative group, with 23 of the 30 patients (76.7\%) improving after surgery as compared with 21 patients $(70 \%)$ improving in the HIV-positive group (Table 4). However, this difference was not statistically significant.

\section{Mortality}

As mentioned earlier, known outcome at follow-up was available in 21 patients in the HIV-negative group and in 26 patients in the HIV-negative group. Of the $21 \mathrm{HIV}$ -

TABLE 3. CD4 analysis with corresponding Palur grade and longterm outcome*

\begin{tabular}{lllll}
\hline \multirow{2}{*}{ Variable } & \multicolumn{3}{c}{ CD4 Count (cells/mm $)$} & $p$ \\
\cline { 2 - 4 } & $<100$ & $100-200$ & $>200$ & Value \\
\hline Long-term outcome & & & & 0.244 \\
\hline Good (GOS Score 4 or 5) & $1(14.3)$ & 0 & $5(71.4)$ & \\
\hline Bad (GOS Score 1-3) & $6(85.7)$ & $3(100)$ & $2(28.6)$ & \\
\hline Palur grade & & & & 0.457 \\
\hline I-II & $1(11.1)$ & $2(40)$ & $2(25)$ & \\
\hline III-IV & $8(88.9)$ & $3(60)$ & $6(75)$ & \\
\hline
\end{tabular}

* Values are number of patients (\%).
TABLE 4. Outcome analysis with respect to the HIV status of the patient*

\begin{tabular}{lccc}
\hline \multirow{2}{*}{ Outcome } & \multicolumn{2}{c}{ No. of Patients (\%) } & \multirow{2}{*}{} \\
\cline { 2 - 3 } & HIV Positive & HIV Negative & Value \\
\hline Death & $14 / 21(66.7)$ & $8 / 26(30.8)$ & 0.014 \\
\hline Long-term outcome & & & 0.005 \\
\hline Good (GOS Score 4 or 5) & $5 / 21(23.8)$ & $17 / 26(65.4)$ & \\
\hline Poor (GOS Score 1-3) & $16(76.2)$ & $9 / 26(34.6)$ & \\
\hline Short-term outcome & & & 0.559 \\
\hline Good (GOS Score 4 or 5) & $21(70.0)$ & $23(76.7)$ & \\
\hline Poor (GOS Score 1-3) & $9(30)$ & $7(23.3)$ & \\
\hline
\end{tabular}

* Values in boldface are statistically significant.

positive patients, 14 patients $(66.67 \%)$ had died at followup, while in the HIV-negative group, 8 of the 26 patients had died (30.7\%). In the 1st month following shunt placement, there was high mortality with 8 of 14 deaths in the HIV-positive group, and 6 of 8 deaths in the HIV-negative group occurring within the first 30 days. Four patients died within 1-6 months of shunt placement in the HIVpositive group, compared with only 2 deaths in HIV-negative group. Two patients in the HIV-positive group died after 6 months, while there were no deaths in the HIVnegative group. Morbidity was significantly higher in the HIV-positive group than in the HIV-negative group ( $\mathrm{p}=$ 0.014) (Table 4).

We also analyzed mortality with GCS score at presentation, and divided the patients into 3 groups based on GCS score (Group 1: GCS Scores 3-8; Group 2: GCS Scores 9-12; and Group 3: GCS Scores 13-15). As expected, there was high mortality in patients with GCS Scores 3-8 and 9-12 in both groups. Three of the 4 patients in the HIV-positive group with GCS Scores 3-8 died, while the only patient in the HIV-negative group with a GCS score lower than 8 died. Similar trends were seen in the GCS Score 9-12 group, with 8 of 9 patients in the HIV-positive group and 5 of 7 patients in the HIV-negative group who died. However, there was significantly higher mortality in patients with GCS Scores 13-15 in the HIV-positive group (3 of 8 [37.5\%]) than in the HIV-negative group (2 of 18 $[11.1 \%])$.

\section{Long-Term Outcome}

Long-term outcome was assessed using the GOS. Only $5(23.8 \%)$ of 21 patients had favorable outcomes in the HIV-positive group, compared with 17 (79.9\%) of 26 patients in the HIV-negative group $(\mathrm{p}=0.005)$. Hence, seropositivity for HIV was an independent predictor of longterm outcome in patients with TBM. As mentioned before, there was significantly higher mortality in the HIV-positive group than in the HIV-negative group.

\section{Variables Affecting Long-Term Outcome}

Long-term outcome was assessed using the GOS; a favorable outcome was considered to be a good recovery or mild disability (GOS Score 4 or 5). On univariate analysis, GCS score at presentation was the most important factor 
determining the long-term outcome, with all patients with GCS Scores 3-8 having poor neurological outcome, while 22 of 42 patients (52.4\%) with GCS Scores 9-15 had good outcome. A poor GCS score was associated with poor outcome in HIV-negative and HIV-positive patients. However, due to small numbers of patients with GCS Scores 3-8, it did not attain statistical significance. Patients in Palur Grades I and II had significantly better outcome than patients in Grades III and IV. Significantly, in HIV-positive patients, 4 of the 5 patients $(80 \%)$ in Palur Grades I and II had good outcome at follow-up.

HIV seropositivity was significantly associated with a poor outcome. Only 5 of 21 patients $(23.8 \%)$ in the HIVpositive group had good outcome at follow-up, while 17 of 26 patients $(65.4 \%)$ in the HIV-negative group had good long-term outcome $(\mathrm{p}=0.005)$. Presence of anemia was a poor prognostic factor in HIV-positive patients, but it did not affect outcome in HIV-negative patients. No other factor had a significant effect on long-term outcome (Table 5).

CD4 counts were available for only 17 HIV-positive patients who had follow-up. We analyzed our results after dividing the available CD4 counts into 3 groups $(<100$, 100-200, and $>200$ cells $/ \mathrm{mm}^{3}$ ) (Table 3). Long-term outcome was analyzed in relation to the 3 groups. Although CD4 count was not predictive of long-term outcome in the patients, it is worth mentioning that only 1 patient $(14.3 \%)$ with a CD4 count lower than 100 cells $/ \mathrm{mm}^{3}$ had good outcome.

\section{Multivariate Analysis}

Multivariate regression analysis was done by binary logistic regression for various variables predicting the long-term outcome. Seropositivity was independently associated with unfavorable outcome $(\mathrm{p}=0.038)$. Besides HIV-positive status, low Palur TBM grade at presentation significantly affected the outcome in both HIV-positive and HIV-negative patients $(\mathrm{p}=0.024)$. The present study showed that the presence of anemia was a significant factor for unfavorable outcome (Table 6). Other radiological features and clinical features were not significantly associated with long-term outcome.

\section{Discussion \\ TBM and HIV}

The number of tuberculosis cases in the world is increasing. Most of these new cases are in south East Asian countries like China and India as reported by the Global Tuberculosis Report: 2012.32 With emergence of AIDS and the use of immunosuppressive therapy, the incidence of TBM is also increasing in developed countries. ${ }^{13}$ Moreover, coexistence of TBM in HIV-positive patients comes under the definition of AIDS according to the World Health Organization clinical case definition. Many previous studies have reported high mortality in TBM patients who are HIV positive. ${ }^{30,31}$ Thwaites et al., in their series of 545 cases, reported a mortality of $64.6 \%$ in HIV-positive patients compared with $28.2 \%$ in HIV-negative patients. ${ }^{26}$ Another study in India also reported higher mortality at 6 months in HIV-positive patients (36\% vs $10 \%) .{ }^{11}$
In various studies, few differences have been noted between clinical presentation and biochemical markers in TBM between HIV-positive and HIV-negative patients. In a study by Katrak et al., the clinical features between the 2 groups were similar, although cognitive disturbances were higher in the HIV-positive group. ${ }^{11}$ Yechoor et al. reported that the most common symptoms of TBM associated with HIV infection were fever $(83 \%)$ and abnormal mental status $(71 \%)$, which was no different from the findings in HIV-negative individuals. ${ }^{33}$ In this study, apart from the constitutional symptoms, which were higher in HIV-negative patients, there were no differences in the clinical presentation. The present study noted that more HIV-positive patients had extrameningeal tuberculosis (15 of 30) than HIV-negative patients (11 of 30). Hyponatremia was present in a higher proportion of HIV-positive patients. With regard to the CSF values, the CSF leukocyte count was higher in HIV-positive group. However, these differences were not statistically significant.

Many authors have reported similar radiological abnormalities in both HIV-positive and HIV-negative patients. ${ }^{21,30}$ It has been noted that there is a lower incidence of basal exudates and obstructive hydrocephalus in HIVpositive patients not taking antiretroviral treatment. ${ }^{11}$ In the present study, basal exudates were less common in TBM patients who were HIV positive (13 [43.3\%]) than in those who were HIV negative (17 [56.6\%]). The incidence of infarcts in HIV-positive patients (7 of 30 [23.3\%]) was similar to that in HIV-negative patients (9 of 30 [30\%]). Tuberculomas were seen more commonly in the HIV-negative patients than in the HIV-positive group. However, none of these differences in the radiological parameters between the 2 groups were statistically significant in the present study.

\section{CSF Diversion in TBM With HIV}

HIV-associated TBM poses significant diagnostic and therapeutic challenges and carries a dismal prognosis. ${ }^{11,25,28}$ Furthermore, the presence of hydrocephalus in TBM patients is associated with a much poorer prognosis. ${ }^{7,17}$ Literature regarding the optimal surgical management of TBMrelated hydrocephalus in HIV-infected patients is scarce. Nadvi et al. ${ }^{18}$ reported a dismal prognosis at 1-month follow-up in patients who underwent VP shunt insertion. They concluded that all HIV-associated TBM patients with hydrocephalus should be considered as being in Grade III or IV and advised against immediate insertion of shunts, irrespective of their CD4 counts. The study further proposed a trial of ventricular or lumbar CSF drainage for 24-48 hours, and only those who demonstrate significant improvement in their neurological status should proceed to shunt surgery. There was high mortality in the series. Ten of 15 HIV-infected patients died compared with 4 of 15 HIV uninfected patients. No patient in the HIV-positive group demonstrated any clinical improvement after shunt placement.

In the present study, the prognosis for the HIV-positive patients was poor. However, unlike the previous reports, 4 of 5 patients in good grades had good long-term outcome, while only 1 of 16 patients in poor grades had a good outcome. Therefore, while shunt treatment in poor- 
TABLE 5. Variables affecting long-term outcome in HIV-positive and HIV-negative patients*

\begin{tabular}{|c|c|c|c|c|c|c|c|c|c|}
\hline \multirow[b]{2}{*}{ Variable } & \multirow[b]{2}{*}{ Division } & \multicolumn{4}{|c|}{ HIV Positive } & \multicolumn{4}{|c|}{ HIV Negative } \\
\hline & & $\begin{array}{c}\text { No. of } \\
\text { Patients }\end{array}$ & $\begin{array}{c}\text { Good } \\
\text { Outcome }\end{array}$ & $\begin{array}{c}\text { Poor } \\
\text { Outcome }\end{array}$ & $\begin{array}{c}p \\
\text { Value }\end{array}$ & $\begin{array}{c}\text { No. of } \\
\text { Patients }\end{array}$ & $\begin{array}{c}\text { Good } \\
\text { Outcome }\end{array}$ & $\begin{array}{c}\text { Poor } \\
\text { Outcome }\end{array}$ & $\begin{array}{c}p \\
\text { Value }\end{array}$ \\
\hline \multirow{2}{*}{ Age in yrs } & $\leq 30$ & 8 & 2 & 6 & 0.920 & 16 & 11 & 5 & \multirow{2}{*}{$-0.64 \varepsilon$} \\
\hline & $>30$ & 13 & 3 & 10 & & 10 & 6 & 4 & \\
\hline \multirow{2}{*}{ Sex } & Male & 15 & 4 & 11 & 0.627 & 20 & 13 & 7 & \multirow{2}{*}{0.940} \\
\hline & Female & 6 & 1 & 5 & & 6 & 4 & 2 & \\
\hline \multirow{2}{*}{ Duration of symptoms in days } & $\leq 21$ & 15 & 4 & 11 & 0.627 & 15 & 12 & 3 & \multirow{2}{*}{0.067} \\
\hline & $>21$ & 6 & 1 & 5 & & 11 & 5 & 6 & \\
\hline \multirow{2}{*}{ Previous tuberculosis history } & Yes & 8 & 2 & 6 & 0.920 & 11 & 6 & 5 & \multirow{2}{*}{0.32} \\
\hline & No & 13 & 3 & 10 & & 15 & 11 & 4 & \\
\hline \multirow{2}{*}{ Headache } & Yes & 15 & 4 & 11 & 0.627 & 19 & 12 & 7 & \multirow{2}{*}{0.694} \\
\hline & No & 6 & 1 & 5 & & 7 & 5 & 2 & \\
\hline \multirow{2}{*}{ Fever } & Yes & 13 & 4 & 9 & 0.340 & 22 & 15 & 7 & \multirow{2}{*}{0.48} \\
\hline & No & 8 & 1 & 7 & & 4 & 2 & 2 & \\
\hline \multirow{2}{*}{ Seizure } & Yes & 6 & 0 & 6 & 0.105 & 4 & 3 & 1 & \multirow{2}{*}{0.660} \\
\hline & No & 15 & 5 & 10 & & 22 & 14 & 8 & \\
\hline \multirow{2}{*}{ Preop GCS score } & $3-8$ & 4 & 0 & 4 & 0.214 & 1 & 0 & 1 & \multirow{2}{*}{-0.161} \\
\hline & $9-15$ & 17 & 5 & 11 & & 25 & 17 & 8 & \\
\hline \multirow{2}{*}{ Palur grade } & $|\&| \mid$ & 5 & 4 & 1 & 0.030 & 9 & 8 & 1 & \multirow{2}{*}{0.067} \\
\hline & III \& IV & 16 & 1 & 15 & & 17 & 9 & 8 & \\
\hline \multirow{2}{*}{ Meningeal sign } & Yes & 17 & 5 & 12 & 0.214 & 12 & 8 & 4 & \multirow{2}{*}{0.899} \\
\hline & No & 4 & 0 & 4 & & 14 & 9 & 5 & \\
\hline & Yes & 4 & 2 & 2 & 0.172 & 8 & 5 & 3 & \\
\hline Cranial nerve & No & 17 & 3 & 14 & & 18 & 12 & 6 & 0.831 \\
\hline Focal deficit & Yes & 3 & 1 & 2 & 0.676 & 8 & 3 & 5 & 0116 \\
\hline rocal dencil & No & 18 & 4 & 14 & & 18 & 14 & 4 & 0.110 \\
\hline & Communicating & 16 & 3 & 13 & 0.330 & 20 & 13 & 7 & 0.940 \\
\hline ryarocepnalus & Noncommunicating & 5 & 2 & 4 & & 6 & 4 & 2 & 0.940 \\
\hline & Present & 17 & 4 & 13 & 0.950 & 23 & 14 & 9 & \\
\hline PVL & Absent & 4 & 1 & 3 & & 3 & 3 & 0 & 0.180 \\
\hline Fxudates & Present & 9 & 3 & 6 & 0.467 & 16 & 8 & 8 & 0.070 \\
\hline Exudates & Absent & 12 & 2 & 10 & & 10 & 9 & 1 & 0.010 \\
\hline Infarct & Present & 6 & 2 & 4 & 0.517 & 8 & 4 & 4 & 0118 \\
\hline marct & Absent & 15 & 3 & 12 & & 18 & 13 & 5 & 0.110 \\
\hline Tuberculoma & Present & 2 & 1 & 1 & 0.218 & 7 & 5 & 2 & \\
\hline rudercuioma & Absent & 19 & 3 & 16 & & 19 & 12 & 7 & 0.180 \\
\hline & Present & 5 & 1 & 4 & 0.819 & 5 & 3 & 2 & \\
\hline Hyponatremla & Absent & 16 & 4 & 12 & & 21 & 14 & 7 & 0.118 \\
\hline Anemia & Hemoglobin $\leq 10 \mathrm{mg} / \mathrm{dl}$ & 9 & 3 & 6 & 0.350 & 7 & 2 & 5 & 0.017 \\
\hline AIIEIIIa & Hemoglobin $>10 \mathrm{mg} / \mathrm{dl}$ & 12 & 2 & 10 & & 19 & 15 & 4 & 0.011 \\
\hline
\end{tabular}

* Values in boldface are statistically sigificant.

grade HIV-positive patients may not be recommended, it should be considered in good-grade patients without a trial of external ventricular or lumbar drainage.

\section{Hydrocephalus and TBM, With and Without HIV}

In our series, of 60 patients, follow-up information for 21 patients in the HIV-positive group and 26 in the HIVnegative group was available. Mortality was higher in the HIV-positive group (66.67\%) than in the HIV-negative group (30.7\%), which was statistically significant ( $\mathrm{p}=$ $0.014)$.

The highest mortality was in the first 6 months, which is similar to the findings of many previous studies reporting higher rates of death at 6 months after initiation of antituberculosis treatment in HIV-infected patients (24\%-50\%) than to HIV-uninfected patients $(0 \%-22 \%)$. $5,11,12,28,31,33$

Only 5 of 21 patients in the HIV-positive group had a favorable outcome compared with 17 of 26 in the HIV- 
TABLE 6. Multivariate analysis for factors affecting long-term outcome*

\begin{tabular}{|c|c|c|c|c|c|c|}
\hline \multirow[b]{2}{*}{ Variable } & \multirow[b]{2}{*}{ Division } & \multirow[b]{2}{*}{ No. of Patients } & \multirow[b]{2}{*}{$p$ Value } & \multirow[b]{2}{*}{$\operatorname{Exp}(B)$} & \multicolumn{2}{|c|}{$95 \% \mathrm{Cl}$ for $\operatorname{Exp}(\mathrm{B})$} \\
\hline & & & & & Lower & Upper \\
\hline \multirow{2}{*}{ Age } & $<30$ & 21 & \multirow{2}{*}{0.113} & \multirow{2}{*}{6.334} & \multirow{2}{*}{0.645} & \multirow{2}{*}{62.162} \\
\hline & $>30$ & 26 & & & & \\
\hline \multirow{2}{*}{ Sex } & Male & 35 & \multirow{2}{*}{0.663} & \multirow{2}{*}{0.654} & \multirow{2}{*}{0.097} & \multirow{2}{*}{4.410} \\
\hline & Female & 12 & & & & \\
\hline \multirow{2}{*}{ HIV status } & Positive & 21 & \multirow{2}{*}{0.038} & \multirow{2}{*}{11.269} & \multirow{2}{*}{1.148} & \multirow{2}{*}{110.638} \\
\hline & Negative & 26 & & & & \\
\hline \multirow{2}{*}{ Palur grade } & $|\&| \mid$ & 14 & \multirow{2}{*}{0.024} & \multirow{2}{*}{0.025} & \multirow{2}{*}{0.001} & \multirow{2}{*}{0.623} \\
\hline & III \& IV & 33 & & & & \\
\hline \multirow{2}{*}{ Fever } & Present & 33 & \multirow{2}{*}{0.670} & \multirow{2}{*}{0.628} & \multirow{2}{*}{0.074} & \multirow{2}{*}{5.310} \\
\hline & Absent & 14 & & & & \\
\hline \multirow{2}{*}{ Duration of symptoms } & $<21$ & 28 & \multirow{2}{*}{0.545} & 0534 & 0.070 & 4080 \\
\hline & $>21$ & 19 & & ד & 0.010 & 7.000 \\
\hline PYI & Present & 41 & 0860 & 1261 & 0070 & 102 \\
\hline PVL & Absent & 6 & 0.009 & 1.204 & 0.019 & 20.103 \\
\hline Infarct & Present & 22 & 0749 & 1406 & 0175 & 11290 \\
\hline Imarct & Absent & 25 & 0.149 & 1.400 & 0.175 & 11.299 \\
\hline Fyudatec & Present & 13 & 0365 & 0355 & 0038 & 3335 \\
\hline Exurates & Absent & 34 & 0.000 & 0.000 & 0.050 & 0.00 \\
\hline & Present & 7 & 0.440 & 0.325 & 0019 & 5621 \\
\hline Tuberculoma & Absent & 40 & 0.440 & $0.0<0$ & 0.019 & 0.021 \\
\hline & Present & 10 & 0355 & 0391 & 0054 & 2856 \\
\hline Hyponatremia & Absent & 37 & 0.005 & 0.091 & 0.004 & 2.000 \\
\hline Anemia & Hemoglobin $\leq 10 \mathrm{mg} / \mathrm{dl}$ & 16 & 0011 & 25634 & 2101 & 755 \\
\hline Anemla & Hemoglobin $>10 \mathrm{mg} / \mathrm{dl}$ & 21 & 0.071 & 25.034 & 2.101 & 312.105 \\
\hline
\end{tabular}

* Values in boldface are statistically significant.

negative group $(p=0.005)$. The immediate good outcome, which was present in most of the patients in the HIV-positive group, was not reflected in long-term follow-up. Nadvi et al. had a follow-up until 1 month and reported that none of the patients in their series had a good outcome. However, in our series, 3 of the patients who had favorable outcome had a GOS score of 5 .

\section{Variable Affecting the Outcome}

Preoperative GCS score has been shown to be an independent factor affecting outcome after shunt diversion in TBM patients with hydrocephalus., ${ }^{4,619,22}$ This was true in our study, both for HIV-negative and HIV-positive patients. This correlated with previous studies done by Palur et al. ${ }^{19}$ and Mathew et al. ${ }^{14}$ who showed high mortality in poor-grade patients with hydrocephalus. HIV seropositivity was an independent predictor for mortality and poor outcome. Presence of immunosuppression, HIV-related infections, and other factors such as immune reconstitution syndrome, drug resistance, and the social stigma associated with the disease may contribute to the poor outcome in HIV-infected TBM patients.

Besides the patient grade with respect to TBM at presentation and retroviral status, several other factors have been identified as prognostic variables in TBM. Several studies have reported age, presence of cranial nerve palsies, and severity of hydrocephalus as prognostic variables. ${ }^{15}$ Kalita et al., ${ }^{9}$ in their multivariate analysis, recognized the presence of focal motor deficits as the most important predictor of delayed sequelae. Misra et al. ${ }^{16}$ identified presence of focal deficits and infarctions as important predictors of outcome at 3 and 6 months, respectively.

In the present study, anemia had a prognostic correlation with poor outcome (Table 6). Torok et al. found that severe hyponatremia was an independent factor associated with early death in a cohort of HIV-infected TBM patients. ${ }^{29}$ Karande et al. ${ }^{10}$ and Thwaites et al. ${ }^{26}$ had independently reported that moderate to severe anemia is more common in HIV-positive patients and is associated with an unfavorable outcome, which is similar to our findings.

Low CD4 count has been used as an indicator to withhold surgery or intervention in an HIV-positive patient. In our study low CD4 count was uniformly associated with unfavorable outcome. It was also associated with poor grade of TBM presentation; however, there was no statistical significance as shown in (Table 4). One of our patients made good recovery (GOS Score 4) despite having a low CD4 count; therefore, we are of the opinion that low CD4 count should not be considered as a criterion to withhold shunt surgery in a HIV-positive patient. The grade of TBM should guide treatment in such cases. Although HIV se- 
ropositivity was an independent risk factor for mortality and poor outcome, the outcome of good-grade TBM patients was better than that previously reported in literature. Therefore, we advocate shunt treatment for good-grade HIV-positive TBM patients with hydrocephalus, and a trial of external ventricular drainage for poor-grade HIVpositive patients.

There are many limitations to our study. First, being a retrospective study, there is a selection bias in choosing patients for VP shunt placement. Also, not all patients had long-term follow-up data, and this could affect the conclusions. Although we performed a case-bias analysis between the follow-up group and the entire group and showed that the follow-up group is representative of the entire group, still there could be some bias in the conclusions. There might have been inaccuracies in outcome measurement through questionnaires. Finally, GOS and GCS scores are not the best metrics in evaluating patients with TBM and their recovery, but this was done because of ease of use of these scales.

\section{Conclusions}

Tubercular meningitis in HIV-positive patients with hydrocephalus has a very poor outcome. Our study showed that mortality was significantly higher in the HIV-positive group than in the HIV-negative group, and only less than one-quarter of patients in the HIV-positive group had a good outcome. HIV seropositivity is an independent indicator predicting poor outcome. Palur grade, anemia, and hyponatremia are other factors that influence the outcome in these patients.

We recommend that shunting not be done for HIV-positive patients in Palur Grade III and IV who have TBM and hydrocephalus, in view of uniformly poor outcome in these patients. A trial of external ventricular drainage may be instituted, and shunting should be done only if there is any improvement. In our study none of the patients in the HIV-positive group with poor GCS scores (3-8) survived. However, HIV-positive patients in good Palur grades should undergo VP shunt placement, as they have better outcomes than previously reported.

\section{References}

1. Agrawal D, Gupta A, Mehta VS: Role of shunt surgery in pediatric tubercular meningitis with hydrocephalus. Indian Pediatr 42:245-250, 2005

2. Barnes PF, Bloch AB, Davidson PT, Snider DE Jr: Tuberculosis in patients with human immunodeficiency virus infection. N Engl J Med 324:1644-1650, 1991

3. Berenguer J, Moreno S, Laguna F, Vicente T, Adrados M, Ortega A, et al: Tuberculous meningitis in patients infected with the human immunodeficiency virus. N Engl J Med 326:668-672, 1992

4. Berger JR: Tuberculous meningitis. Curr Opin Neurol 7:191-200, 1994

5. Brancusi F, Farrar J, Heemskerk D: Tuberculous meningitis in adults: a review of a decade of developments focusing on prognostic factors for outcome. Future Microbiol 7:11011116,2012

6. Bullock MR, Van Dellen JR: The role of cerebrospinal fluid shunting in tuberculous meningitis. Surg Neurol 18:274277,1982
7. Chan KH, Cheung RT, Fong CY, Tsang KL, Mak W, Ho SL: Clinical relevance of hydrocephalus as a presenting feature of tuberculous meningitis. QJM 96:643-648, 2003

8. Jennett B, Bond M: Assessment of outcome after severe brain damage. A practical scale. Lancet 1:480-484, 1975

9. Kalita J, Misra UK, Ranjan P: Predictors of long-term neurological sequelae of tuberculous meningitis: a multivariate analysis. Eur J Neurol 14:33-37, 2007

10. Karande S, Gupta V, Kulkarni M, Joshi A, Rele M: Tuberculous meningitis and HIV. Indian J Pediatr 72:755-760, 2005

11. Katrak SM, Shembalkar PK, Bijwe SR, Bhandarkar LD: The clinical, radiological and pathological profile of tuberculous meningitis in patients with and without human immunodeficiency virus infection. J Neurol Sci 181:118-126, 2000

12. Marais S, Pepper DJ, Marais BJ, Török ME: HIV-associated tuberculous meningitis - diagnostic and therapeutic challenges. Tuberculosis (Edinb) 90:367-374, 2010

13. Martínez-Martín P: Tuberculous meningitis in patients infected with the human immunodeficiency virus. N Engl J Med 327:1170-1172, 1992 (Letter)

14. Mathew JM, Rajshekhar V, Chandy MJ: Shunt surgery in poor grade patients with tuberculous meningitis and hydrocephalus: effects of response to external ventricular drainage and other variables on long term outcome. J Neurol Neurosurg Psychiatry 65:115-118, 1998

15. Misra SS, Khanna BK: Prognostic factors in tuberculous meningitis. J Indian Med Assoc 36:13-18, 1961

16. Misra UK, Kalita J, Roy AK, Mandal SK, Srivastava M: Role of clinical, radiological, and neurophysiological changes in predicting the outcome of tuberculous meningitis: a multivariable analysis. J Neurol Neurosurg Psychiatry 68:300303,2000

17. Misra UK, Kalita J, Srivastava M, Mandal SK: Prognosis of tuberculous meningitis: a multivariate analysis. J Neurol Sci 137:57-61, 1996

18. Nadvi SS, Nathoo N, Annamalai K, van Dellen JR, Bhigjee AI: Role of cerebrospinal fluid shunting for human immunodeficiency virus-positive patients with tuberculous meningitis and hydrocephalus. Neurosurgery 47:644-650, 2000

19. Palur R, Rajshekhar V, Chandy MJ, Joseph T, Abraham J: Shunt surgery for hydrocephalus in tuberculous meningitis: a long-term follow-up study. J Neurosurg 74:64-69, 1991

20. Rajshekhar V: Management of hydrocephalus in patients with tuberculous meningitis. Neurol India 57:368-374, 2009

21. Schutte CM: Clinical, cerebrospinal fluid and pathological findings and outcomes in HIV-positive and HIV-negative patients with tuberculous meningitis. Infection 29:213-217, 2001

22. Srikantha U, Morab JV, Sastry S, Abraham R, Balasubramaniam A, Somanna $S$, et al: Outcome of ventriculoperitoneal shunt placement in Grade IV tubercular meningitis with hydrocephalus: a retrospective analysis in 95 patients. Clinical article. J Neurosurg Pediatr 4:176-183, 2009

23. Tandon V, Mahapatra AK: Management of post-tubercular hydrocephalus. Childs Nerv Syst 27:1699-1707, 2011

24. Teasdale G, Jennett B: Assessment of coma and impaired consciousness. A practical scale. Lancet 2:81-84, 1974

25. Thwaites G, Chau TT, Mai NT, Drobniewski F, McAdam K, Farrar J: Tuberculous meningitis. J Neurol Neurosurg Psychiatry 68:289-299, 2000

26. Thwaites GE, Duc Bang N, Huy Dung N, Thi Quy H, Thi Tuong Oanh D, Thi Cam Thoa N, et al: The influence of HIV infection on clinical presentation, response to treatment, and outcome in adults with tuberculous meningitis. J Infect Dis 192:2134-2141, 2005

27. Thwaites GE, Schoeman JF: Update on tuberculosis of the central nervous system: pathogenesis, diagnosis, and treatment. Clin Chest Med 30:745-754, ix, 2009

28. Topley JM, Bamber S, Coovadia HM, Corr PD: Tuberculous 
meningitis and co-infection with HIV. Ann Trop Paediatr 18:261-266, 1998

29. Torok ME, Chau TT, Mai PP, Phong ND, Dung NT, Chuong $\mathrm{LV}$, et al: Clinical and microbiological features of HIV-associated tuberculous meningitis in Vietnamese adults. PLoS One 3:e1772, 2008

30. van der Weert EM, Hartgers NM, Schaaf HS, Eley BS, Pitcher RD, Wieselthaler NA, et al: Comparison of diagnostic criteria of tuberculous meningitis in human immunodeficiency virus-infected and uninfected children. Pediatr Infect Dis J 25:65-69, 2006

31. van Well GT, Paes BF, Terwee CB, Springer P, Roord JJ, Donald PR, et al: Twenty years of pediatric tuberculous meningitis: a retrospective cohort study in the western cape of South Africa. Pediatrics 123:e1-e8, 2009

32. World Health Organization: Global Tuberculosis Report: 2012. Geneva: WHO, 2012 (http://apps.who.int/ iris/bitstream/10665/75938/1/9789241564502_eng.pdf) [Accessed January 26, 2015]

33. Yechoor VK, Shandera WX, Rodriguez P, Cate TR: Tuber- culous meningitis among adults with and without HIV infection. Experience in an urban public hospital. Arch Intern Med 156:1710-1716, 1996

\section{Author Contributions}

Conception and design: Pandey, Pruthi. Acquisition of data: Pandey, Sharma. Analysis and interpretation of data: Pandey, Sharma, Pruthi. Drafting the article: Pandey, Arimappamagan. Critically revising the article: Pandey, Pruthi, Arimappamagan, Devi. Reviewed submitted version of manuscript: Pandey, Pruthi, Somanna, Devi. Approved the final version of the manuscript on behalf of all authors: Pandey. Statistical analysis: Pandey, Sharma. Administrative/technical/material support: Pandey, Somanna, Devi. Study supervision: Pandey, Pruthi, Somanna, Devi.

\section{Correspondence}

Paritosh Pandey, Department of Neurosurgery, NIMHANS, Bangalore 560029, India. email: paritosh2000@gmail.com. 